\title{
CONDUCTA EN EL SÍNDROME DE VENA CAVA SUPERIOR (SVCS)*
}

\author{
Drs. Eduardo Arribalzaga F. ${ }^{1}$, Marcos Aguirre V. ${ }^{1}$, Cristian Corchuelo P. ${ }^{1}$ \\ 1 División Cirugía Torácica del Hospital de Clínicas, Buenos Aires. \\ Argentina.
}

\begin{abstract}
Management in superior vena cava syndrome

Objectives: Management in this syndrome. Material and Methods: Retrospective series of 5 cases treated between April 1, 1995 to March 31, 2013. Diagnostic imaging and taking biopsy with subsequent specific treatment. Results: All patients were due to tumor causes: 2 thymomas (one unresectable), 1 lymphoma Hodgkin, 1 Leiomyosarcoma of vena cava and 1 case of small cell lung cancer. Died of disease progression 2 cases, 2 are free of disease to 12 and 11 months of treatment and 1 patient was lost to follow-up. Conclusions: The need to follow an algorithm which determines the steps to follow in the presence of this syndrome is defined.
\end{abstract}

Key words: Mediastinal tumor, superior vena cava, diagnosis, treatment.

\section{Resumen}

Objetivos: Mostrar la conducta realizada en este síndrome. Material y Métodos: Serie retrospectiva de 5 casos tratados entre el 1 de abril de 1995 y el 31 de marzo de 2013. Diagnóstico por imágenes y toma de biopsia con tratamiento específico posterior. Resultados: Todos se debieron a causas tumorales: 2 timomas (uno irresecable), 1 linfoma Hodgkin, 1 leiomiosarcoma de vena cava y 1 caso de cáncer pulmonar a pequeñas células. Fallecieron por progresión de enfermedad 2 casos, 2 están libres de enfermedad a 12 y 11 meses de tratamiento y 1 enfermo se perdió en el seguimiento. Conclusiones: Se define la necesidad de seguir un algoritmo que determine los pasos a seguir ante la presencia de este síndrome.

Palabras clave: Tumor mediastinal, vena cava superior, diagnóstico, conducta.

\footnotetext{
*Recibido el 16 de abril de 2013 y aceptado para publicación el 12 de julio de 2013.

Sin subsidio de investigación. Ningún conflicto de interés.

Correspondencia: Dr. Eduardo Arribalzaga F. Avenida Rivadavia 4282 Piso $4^{\circ}$ Depto. H Ciudad Autónoma de Buenos Aires. CP: C1205AAP Argentina. piedralta@hotmail.com
} 


\section{Introducción}

El Síndrome de la vena cava superior (SVCS) es una histórica entidad nosológica que se presenta como infrecuente, caracterizada por la aparición en forma simultánea de una enfermedad vascular y otra benigna o maligna. Descrita desde 1757, por Hunter como una obstrucción parcial o completa de la vena cava superior ${ }^{1}$, la mayoría de los casos descritos originalmente eran producidos por una infección, en la actualidad se los asocia con la presencia de un dispositivo intravascular ${ }^{2,3}$ o un tumor mediastínico ${ }^{3,5}$, con incidencia aproximada de 1.500 pacientes/año en Argentina ${ }^{4}$ y de 15.000 pacientes/año en Estados Unidos de Norteamérica ${ }^{6}$.

A menudo coexisten múltiples mecanismos patológicos subyacentes para asignar el riesgo de la aparición de un síndrome de vena cava superior, que puede presentar formas clínicas diferentes según la localización de la obstrucción.

El objetivo del presente artículo es mostrar la conducta realizada y los resultados observados en un hospital universitario estatal.

\section{Material y Métodos}

Serie retrospectiva observacional de casos desde el 01 de abril de 1995 al 31 de marzo de 2013 internados en la División Cirugía Torácica con síndrome manifiesto de obstrucción de vena cava superior:

\section{Caso 1}

Mujer de 63 años de edad con edema en cabeza, cuello y miembros superiores, congestión y circulación venosa colateral y turgencia yugular permanente (Figura 1). Refería disnea leve, con disfonía y estridor. En la radiografía de tórax frente, en tomografía computarizada (TC) y angiorresonancia de tórax, se advertía lesión que comprometía la vena cava superior (Figura 2). Se decidió conducta qui- rúrgica de resección. El hallazgo fue un tumor que involucraba toda la vena cava superior; se extirpó con circulación cardíaca extracorpórea y colocación de prótesis para formar una neo cava. En la pieza operatoria se observaba que el tumor involucraba la luz vascular. Biopsia: leiomiosarcoma. En la evolución postoperatoria, se indicó 20 sesiones de radioterapia; a los 4 años su evolución fue desfavorable pero sin síndrome de vena cava superior y falleció por progresión de la enfermedad con metástasis bronquiales.

\section{Caso 2}

Mujer de 32 años de edad con edema de cabeza y cuello, circulación colateral en sector superior del tórax y ortopnea (Figura 3). En radiografías y TC de tórax, presencia de imágenes compatibles con conglomerado adenopático mediastínico. Se realizó mediastinostomía izquierda con anestesia general y el informe biópsico fue linfoma de Hodgkin clásico. Se indicó quimioterapia. Libre de enfermedad al año de la consulta quirúrgica.

\section{Caso 3}

Varón de 59 años de edad, fumador de 40 cig/ día desde hacía más de 35 años, que consultó por estridor, disfonía y tos seca. Dormía sentado. En las tomografías de tórax se observaban imágenes compatibles con adenopatías mediastinales en el opérculo torácico (Figuras 4 a y b) e imágenes nodulares pulmonares bilaterales, la mayor en lóbulo medio pulmonar derecho (Figura 5). La noche previa a la realización de mediastinoscopia, por presentar cianosis y disnea grado III-IV, se realizó traqueostomía de urgencia, recuperando su estabilidad hemodinámica y respiratoria (Figura 6). En esa oportunidad se mandó a biopsia tejido compatible con adenopatías pretraqueales, que informó metástasis ganglionar de carcinoma indiferenciado de células pequeñas de pulmón. Se indicó quimioterapia, falleció a los 2 meses de realizada la consulta quirúrgica.
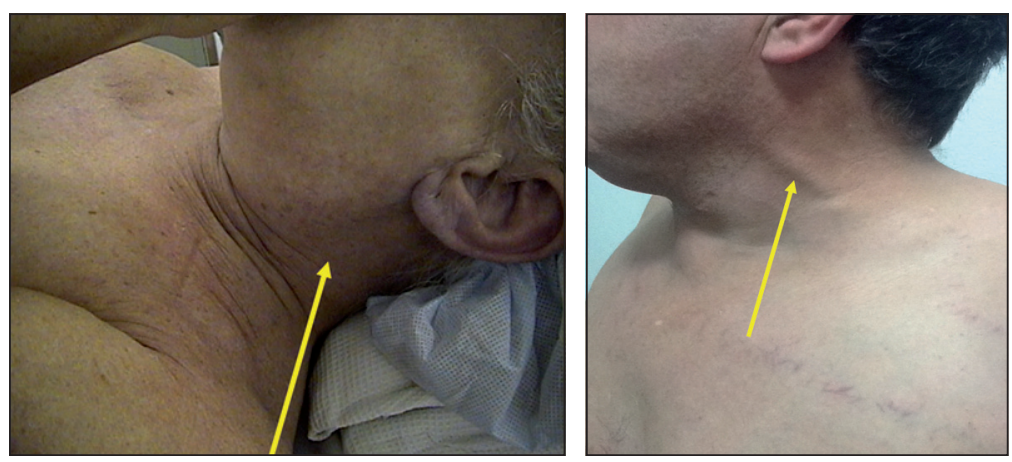

Figura 1. Turgencia yugular permanente en casos 1 y 3 . 


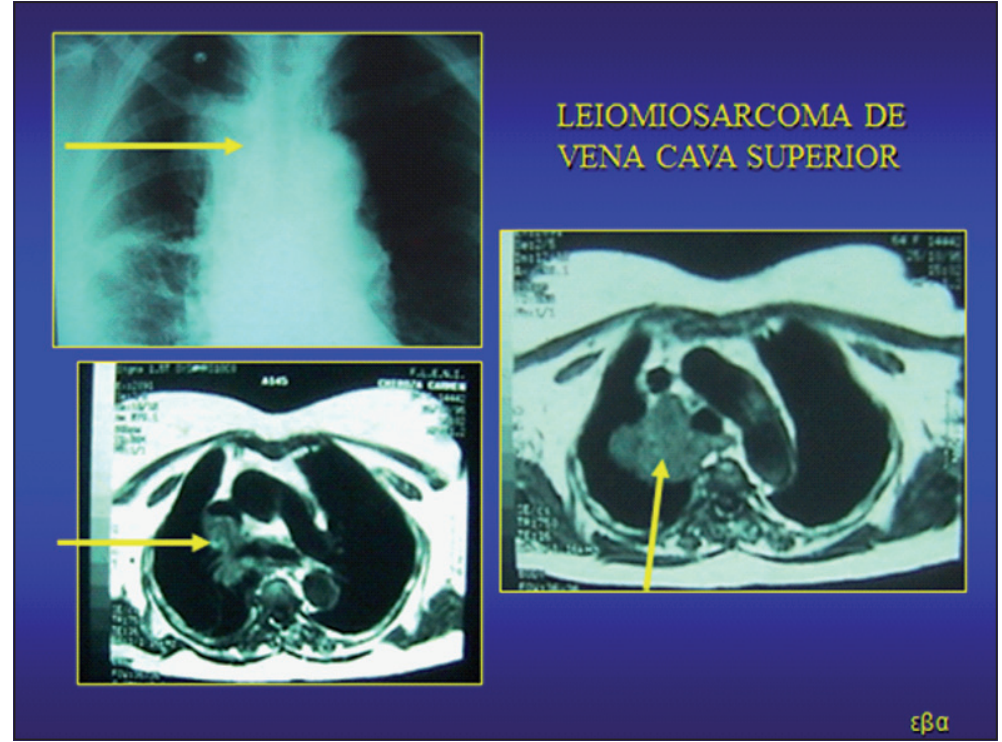

Figura 2. Imagen tumoral en angiorresonancia.

Figura 3. Caso 2: Adenopatías en mediastino anterosuperior.
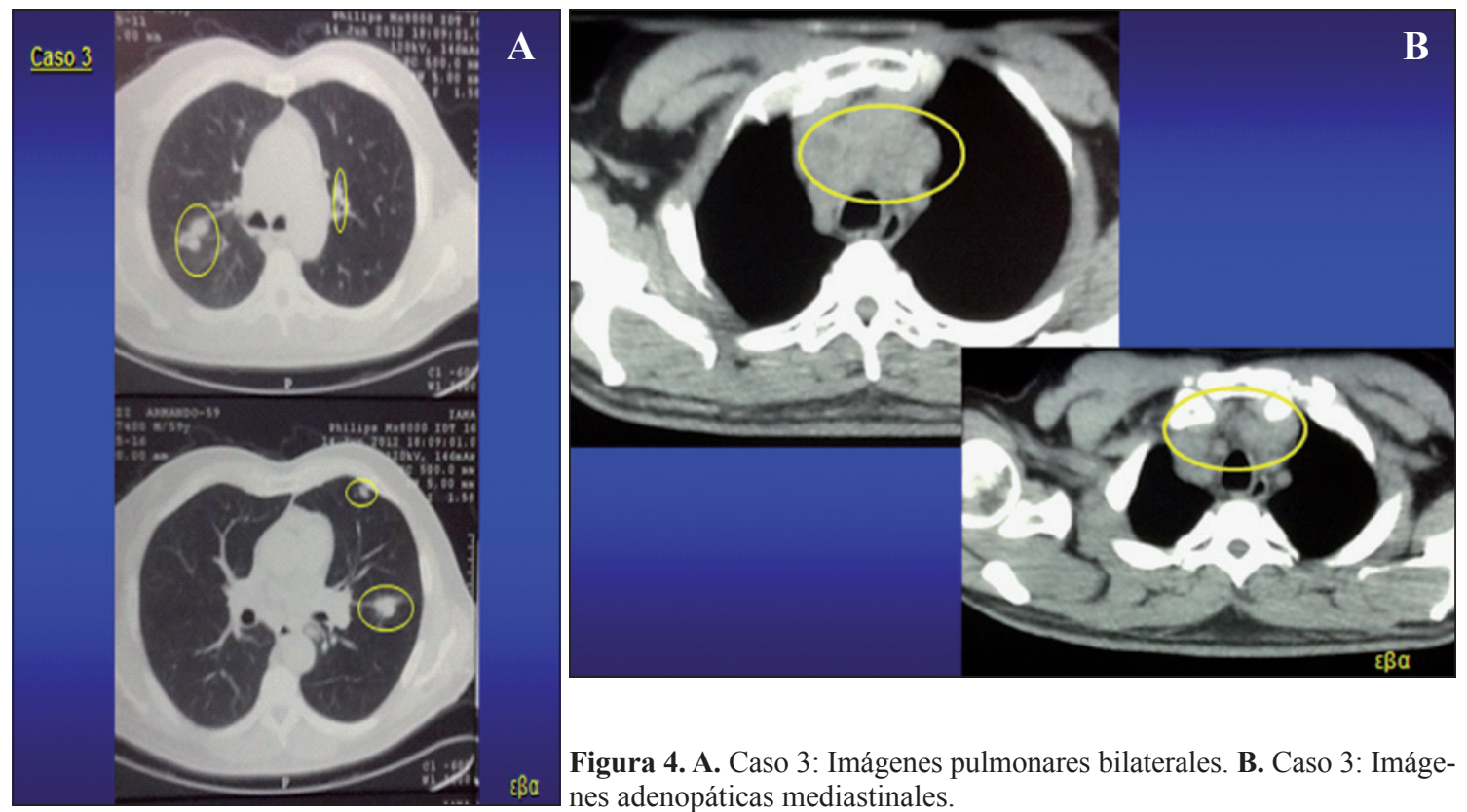

Figura 4. A. Caso 3: Imágenes pulmonares bilaterales. B. Caso 3: Imágenes adenopáticas mediastinales. 

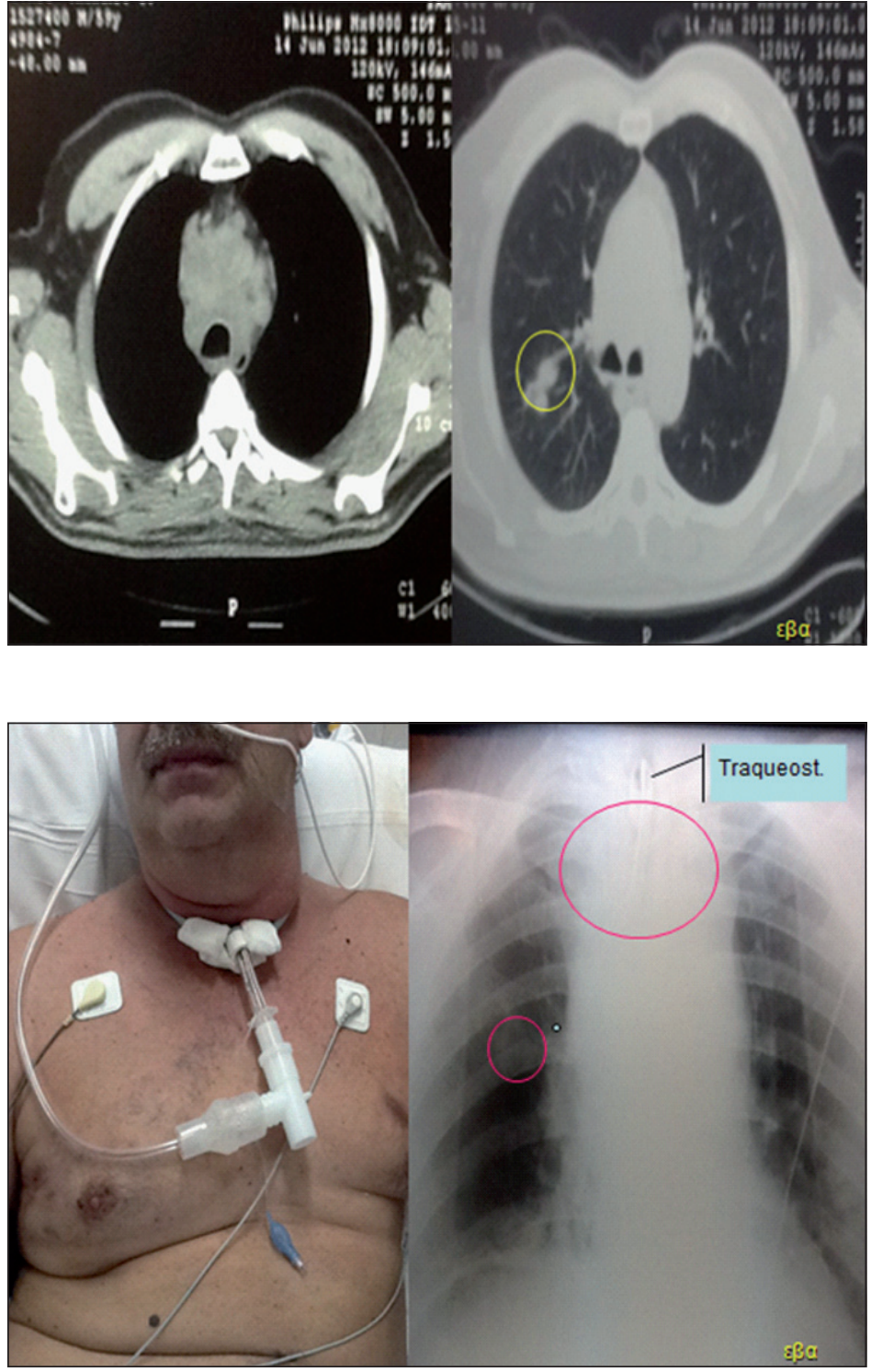

Figura 5. Caso 3: Imagen nodular en lóbulo pulmonar derecho (oat Cell).
Figura 6. Caso 3: Traqueostomía de urgencia. En círculos imagen mediastinal e imagen pulmonar derecha.

\section{Caso 4}

Mujer de 24 años de edad que consultó por disnea y tos. En radiografía de tórax (Figura 7) se observaba una formación tumoral sólida en mediastino anterosuperior; se realizó mediastinostomía derecha que demostró invasión de vena cava superior irresecable y la biopsia informó Timoma B1 según clasificación histológica de la OMS. En el postoperatorio se indicó radioterapia y se perdió control postoperatorio a los 2 meses.

\section{Caso 5}

Mujer de 74 años de edad, que comenzó 1 año antes con disnea clase funcional II. En TC de tó- rax (Figura 8) se veía formación con densidad de partes blandas de $7 \mathrm{~cm}$ de diámetro en mediastino anterosuperior, en contacto con cayado aórtico y desplaza el resto de estructuras vasculares. Se realizó esternotoracotomía exploradora y el hallazgo fue un tumor tímico cuya biopsia fue informada como Timoma AB. Evolución satisfactoria a 11 meses del postoperatorio.

\section{Discusión}

El compromiso de la vena cava superior o sus afluentes origina un síndrome mediastínico superior 


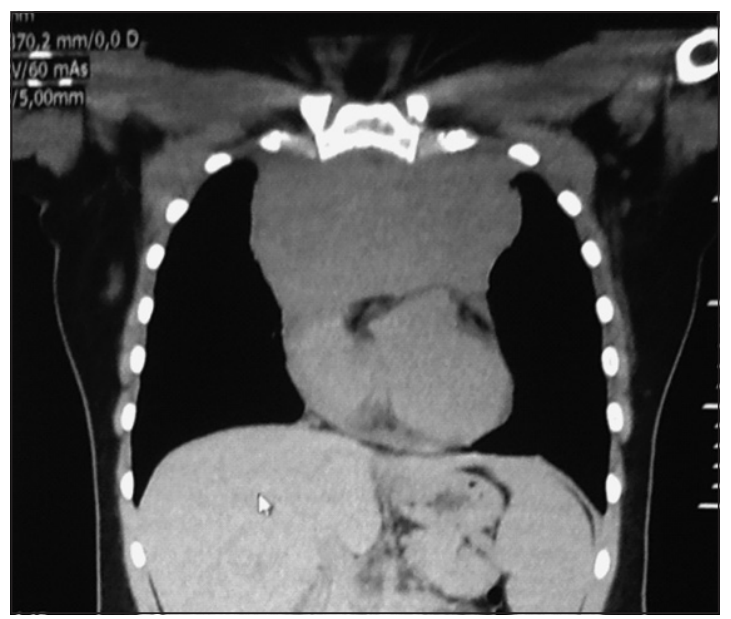

Figura 7. Caso 4: Imagen coronal de mediastino.

consistente en edema de cabeza, cuello y brazos, cianosis, congestión y circulación venosa central y provoca, entre otros síntomas, tos, disfonía, disnea y/o estridor y disfagia, cefalea, somnolencia, zumbidos de oídos debido al edema cerebral y aumento del diámetro del cuello. La compresión vascular, principalmente venosa, se produce en un espacio relativamente reducido y es esta condición anatómica la explicación de la diversidad de síntomas y signos con un compromiso hemodinámico manifiesto.

La distensión de la vena yugular con ausencia de

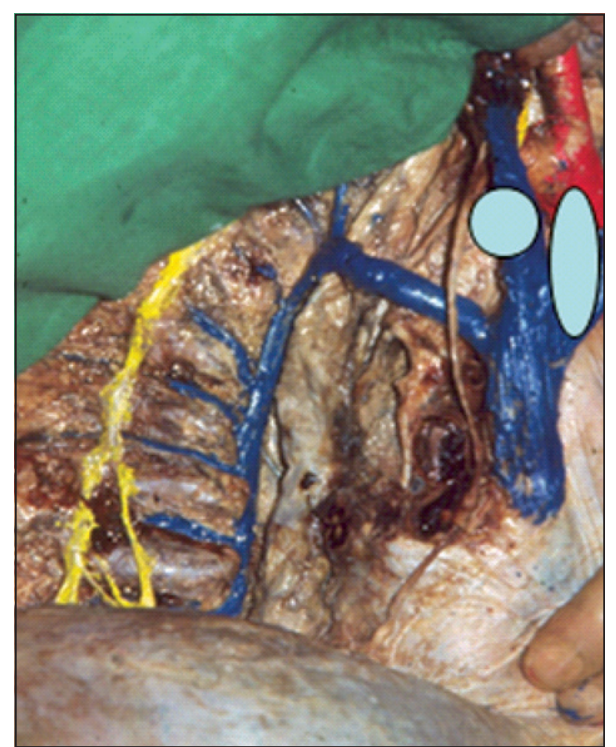

Figura 9. Preparado anatómico con obstrucción infraácigos.

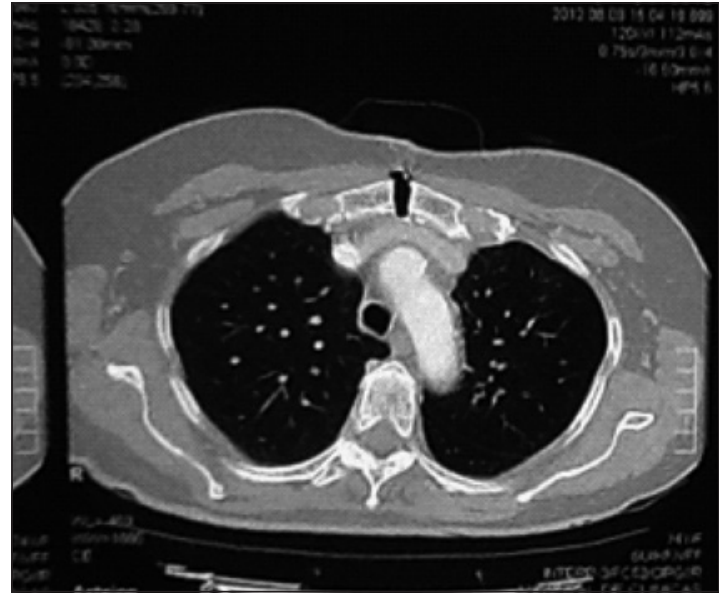

Figura 8. Caso 5: Se ve imagen prevascular con dilatación venosa supraácigos.

latidos en el extremo de la columna venosa no modificada con la inspiración, es signo patognomónico de compresión por encima del cayado de la vena ácigos (Figura 9). La sangre retorna a la vena cava superior por las venas mamarias y costoaxilares y no es particularmente apreciable la circulación venosa colateral en la pared torácica. Si la obstrucción ocurre por debajo del cayado de la vena ácigos (Figura 10), la sangre se deriva a la vena cava inferior a través de las venas lumbares ascendentes e hipogástricas y determina una gran circulación venosa

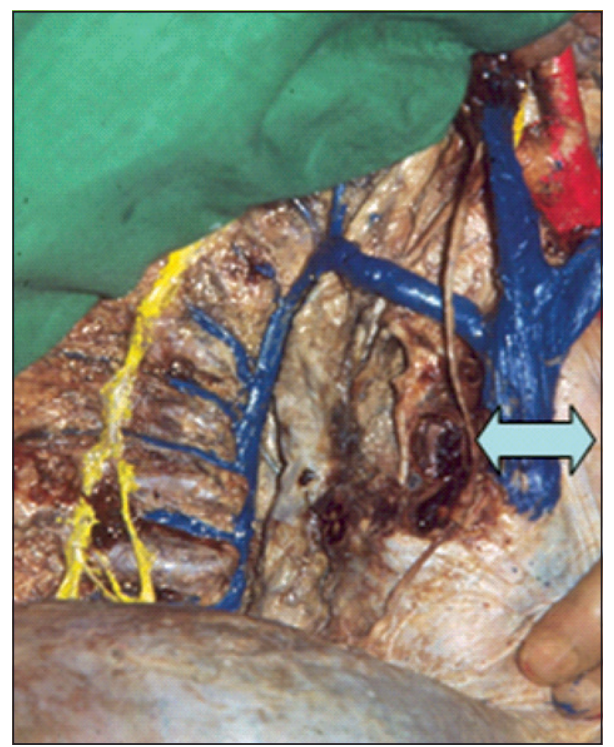

Figura 10. Preparado anatómico con obstrucción supraácigos. 
colateral toracoabdominal, con edema de miembros inferiores en casos extremos. Si existe obstrucción de cualquiera de los troncos venosos innominados, hay ingurgitación yugular, edema, cianosis y aparición de circulación colateral transversal al eje mayor del cuello y tórax (Figura 11). Todos estos signos y síntomas aparecen paulatinamente a partir de 2 semanas de comprimir el sistema venoso de la cava.

Las causas originarias de este síndrome pueden ser benignas (procesos inflamatorios agudos, aneurismas del cayado aórtico, bocios tiroideos sumergidos) en un $15-40 \%$ de los $\operatorname{casos}^{4}$ o malignas ${ }^{5}$ en un $60-85 \%$ de las veces (cáncer pulmonar, linfoma, adenopatías metastásicas, timomas, enfermedades hematológicas). Dentro de las causas benignas, actualmente aumenta la incidencia de trombosis en la vena cava superior y su consecuente síndrome debido al uso intensivo de dispositivos intravasculares como los catéteres venosos centrales o marcapasos cardíacos; además una causa benigna de infrecuente aparición es la fibrosis post-radiación. En la serie aquí presentada, todos los casos originarios de este síndrome eran por causas tumorales.

Aunque el diagnóstico se hace clínicamente, las distintas modalidades de imágenes avanzadas (TC digital, PET-scan) pueden utilizarse para aclarar probable etiología, severidad de grado y facilitar el mejor método diagnóstico biópsico, que en esta serie consistió en un acceso del mediastino anterosuperior mediante mediastinoscopia cervical y/o mediastinostomía anterior para definir el posterior y adecuado tratamiento.

El propósito del manejo de este síndrome es aliviar síntomas y tratar la enfermedad causante y su extensión. La conducta terapéutica del síndrome a menudo requiere una combinación de terapias in- vasivas y no invasivas. La mayoría de la evidencia científica resulta de series de casos ya que existen muy pocos estudios aleatorizados. En cuanto a las estrategias invasivas, la revascularización endovascular es uno de los enfoques a considerar actualmente dada su relativa seguridad y eficacia de primera línea aunque no está exenta de complicaciones ${ }^{2}$.

La expectativa de vida depende de la patología subyacente, pero en los casos de malignidad el promedio es cercano a los 6 meses $^{2}$. En algunos pacientes, como el citado caso 1, el tratamiento de resección y colocación de prótesis vascular con radioterapia posterior llevó a una supervivencia de 4 años. En algunas situaciones, es una urgencia oncológica que requiere la combinación de radioquimioterapia, indicación de oxígeno, diuréticos, corticoides y medidas tan sencillas como elevar la cabecera de la cama del paciente para disminuir la presión hidrostática y por consiguiente el edema cráneo-facio-cervical, con una contraindicación expresa de cirugía hasta estabilizar el cuadro clínico general. El resto de los casos, se trató con quimioterapia en 1 (caso 2), resección quirúrgica completa (caso 5) y en los otros 2 se intentó radio y/o quimioterapia sin obtener resultados favorables en el corto tiempo postoperatorio (2 meses).

En marzo de 2012 se realizó un consenso en Argentina inter-sociedades sobre carcinoma de pulmón no células pequeñas donde se adoptó un algoritmo para el tratamiento del síndrome de vena cava superior (Figura 12). Al no existir una pauta de conducta específica, se sugiere y recomienda el seguimiento de este algoritmo terapéutico con la intención de mejorar los síntomas rápidamente y consolidar el cuadro clínico antes del definitivo tratamiento específico de su causa originaria.

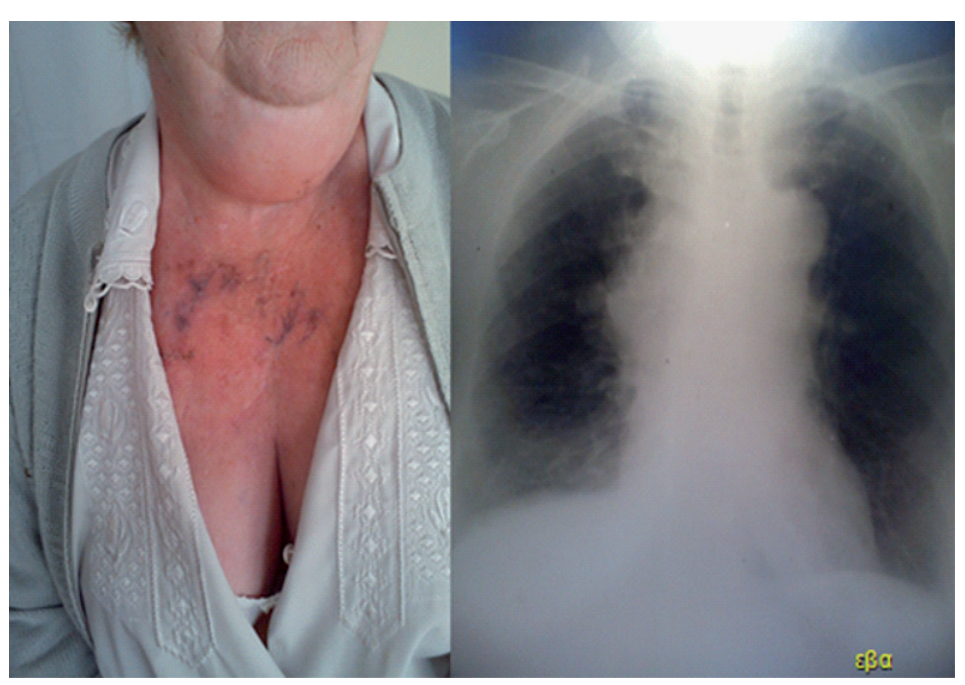

Figura 11. Circulación venosa colateral transversal y edema cervical. 


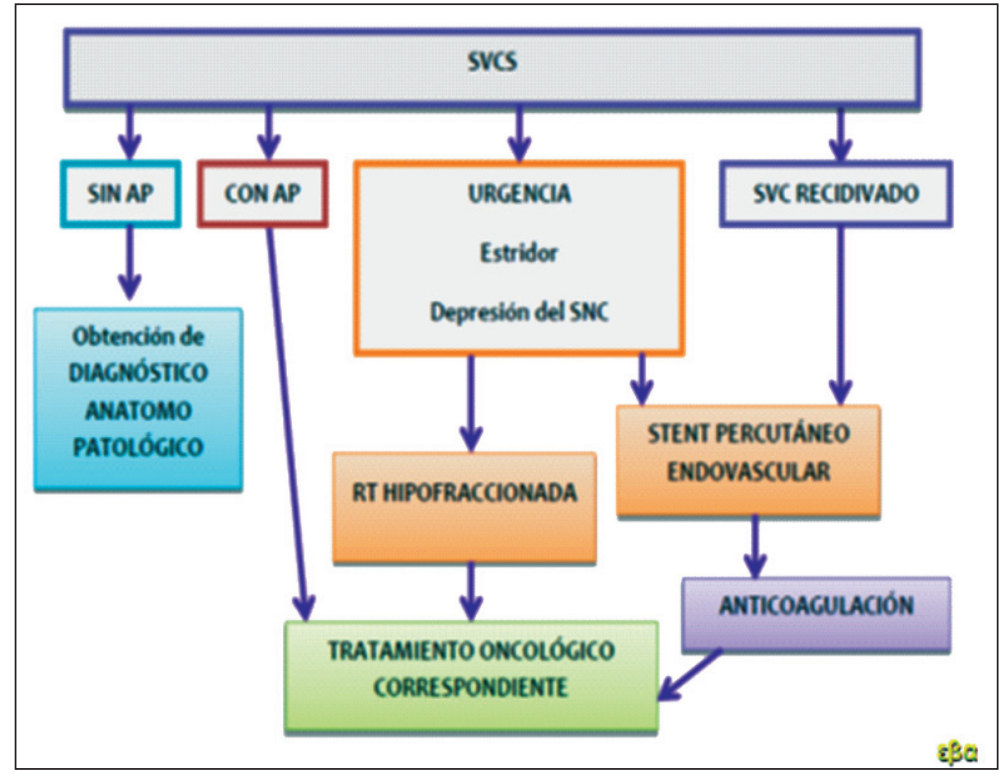

Figura 12. Algoritmo propuesto para conducta en síndrome de vena cava superior (SVCS). AP: anatomía patológica; RT: radioterapia.

\section{Referencias}

1. Cheng S. Superior Vena Cava Syndrome: A contemporary review of a historic disease. Cardiol Rev. 2009; 17:16-23.

2. De Raet JM, Vos JA, Morshuis WJ, van Boven WJ. Surgical management of superior vena cava syndrome after failed endovascular stenting. Interactive Cardiovasc and Thorac Surg. 2012;15:915-7.

3. Luna C. Emergencias oncológicas: síndrome de com- presión mediastinal, clínica, diagnóstico y tratamiento. $14^{\circ}$ Congreso Internacional de Medicina Interna del Hospital de Clínicas, Buenos Aires, 14-17/agosto, 2012.

4. Salazar R, Torrecillas G, Hernández ME. Síndrome de vena cava superior como manifestación inicial de carcinoma tímico. Arch Bronconeumol. 2012;48:3823.

5. Wilson LD, Detterbeck FC, Yahalom J. Superior vena cava syndrome with malignant causes. N Engl J Med. 2007;356:1862-9. 